\section{Hresiduential Adudremsez.}

\section{TREATMENT BY DRUGS :}

\author{
A IIP IN A GENERAL PRACTITIONER'S TOOL-KIT.
}

Delinered before the Btrminghaj Branch of the British Medical Association

BY

H. GUY DAIN, M.B.Loxd., PRESIDENT OF THE BRANCH.

ThE choice of the subject for the presidential address to a Branch of the British Medical Association has in its time, I feel sure, been the cause of much searchings of mind or heart, whichever we prefer to consider the real seat of anxieties and the like. For the specialist in some subject or subjects it is possibly less difficult; but when a man has been in general-very general-practice for many years he has been compelled to familiarize himself with numberless questions and subjects, and at the same time prevented from becoming expert enough at any one to find material for a presidential address. I have found it the more difficult because on this occasion I did not want to drag in my particular " King Charles's head" by addressing you on anything to do with National Health Insurance, or, indeed, any other medico-political subject.

There is, however, one question very much in evidence at the moment. I refer to the tremendous consumption of drugs and their consequent unexpectedly great cost, and it has impressed itself upon me that perhaps something useful might be said in consideration of the question of treatment by the use of drugs.

\section{Treatment of Disease by Drugs.}

To begin with it seems to be often assumed, or at any rate inferred, whenever the subject is dealt with in the press, that drugs in the treatment of diseases are in the main unnecessary and useless, and that when a doctor gives his patient medicine to drink, or a prescription to get it with, he is simply pandering to his patient's desire to gret his cure that way, when he really does not want any medicine at all, but only requires adrice. This is " the fetish of the bottle." I do not in the least agree that this is true as a generalization, though $I$ am fully aware of cases in which it is true; and it cannot be denied that it is much easier and quicker to send off a patient with a prescription, which is all he thinks he wants, than to deal with him more faithfully with advice and instructions as well.

Again, there are among us those whose knowledge of driggs and their uses is, to say the least, elementary and limited to a very short list of common remedies-magnesium sulphate, sodium bicarbonate, rhubarb powder, opium, and perhaps sodium salicylate. These doctor's have not taken much interest in drug treatment, and have not increased their repertoire by the useful methods of trial and error, and experience. They tend to assume that treatment by medicines is largely a process of faith healing, and they are encouraged and comforted in this belief by the fact thoroughly appreciated by us all, that the patient is cured by natural processes in himself, and that the cure is not accomplished by the doctor or his medicine. On the other hand, if one has been interested in trying out remedies, the occasions become very numerous when the patient's troubles can be greatly diminished and the course of his disease favourably modified by appropriate remedies, and I propose to relate here some of my own experiences. In these I do not claim to have any explanation, scientific or otherwise, for the actions or effects observed, but I claim the justification of experience.

In our beginnings and before we qualify we have to learn of drugs and their uses, and we have to know and ke examined on the contents of that wonderful publication the British Pharmacopoeia (the revision and reproduction of which is under consideration now), full of remedies of greater or less potency for all sorts of conditions-many, I am convinced, of very small potency indeed, though widely prescribed. Shall we take, for example, that popular bitter tonic gentian? The value of this is well illustrated by a story of the late Dr. E. Rickards, whose wisdom was well known to many of you. It was observed by one of his students that he frequently ordered an ammonia and gentian mixture, and in search of knowledge the student asked in what circumstances this medicine was prescribed. Dr. Rickards's reply was that he gave that mixture when he did not know what was the matter, when there was nothing the matter, when it did not matter. Other drugs there are of great and well recognized potency, but $I$ have no intention to dwell on the uses of such as are known to t:e specific in the treatment of particular diseases-for example, quinine in malaria, mercury, iodide, and arsenic in syphilis, emetine in amoebic dysentery, salicylates in acute rheumatism, or opium in pain of different kinds.

\section{Diminishing Use of Opium.}

Perhaps the first observation I would make is the steadily diminishing use I find for opium. No! this is not the result of the Dangerous Drugs Act. So many kinds of pain are better relieved by other drugs, and even in the pain of incurable malignant disease, when we are in the end driven to it, $I$ find that the morphine-relieved patient becomes so miserable and mentally altered, and requires so constantly increased a dose that $I$ alwars experiment with combinations of other pain-relievers for as long as possible, in what $I$ believe are the best interests of both the patient and his friends.

While speaking of cancer I am reminded that a man whose wife had been found to have inoperable carcinoma of the cervix uteri once came to me with an old copy of the Lancet, in which a doctor recommended trial of a formula which contained magnesium carbonate 5 grains, potassium citrate 5 grains, alum sulphate 2 grains, tincture of opium 2 minims, in cases of malignant disease, "and asked if it might be tried for his wife. I of course consented, to find to my surprise that in a few days the pain was relieved and the haemorrhage and discharges steadily diminished, and for two years while she took the medicine her symptoms disappeared. She could not be persuaded to take it longer as she was satisfied she was cured. After learing it off for a few months her symptoms returued and the medicine was this time powerless to stay the course of the disease. I have tried the formula since on many occasions, sometimes with apparently helpful results, but only in one other case, and that a pelvic growth, with anything like so surprising an effect.

\section{Catarrhs: Aspirin.}

of the many and varied conditions with which the general practitioner has to deal I suppose it will be agreed that the catarrhs, acute and chronic, of all the various mucous membranes easily outnumber every other complaint, and perhaps there are no other illnesses in which the patient is more grateful for relief. The catarrhs of the respiratory passages are, I suppose, specially and peculiarly prevalent and persistent in our English winter climate. Take the common acute "cold in the nose" with its violent sneezing and profuse dripping-most uncomfortable and very depressing. We all know that it will pass through its various stages and disappear in due course, but the effect, upon many people in the pouring stage, of a few doses of ammonium chloride 10 grains, sodium salicvlate 10 grains, chlorodyne 10 minims, is almost magical, but if the formula is taken to pieces and each constituent tried separately the samo effect cannot be obtained. And when a catarrh has become bronchial and tends to stick $I$ find that I usually turn to creosote and am rarely disappointed in the result. In combination with potassium iodide this remedy will often benefit cases of chronic bronchitis enormously. I have tried these two drugs in the treatment of acute pneumonia, but without any satisfying results. In the management and treatment of acute pneumonia $I$ suppose that in the course of time we all evolve some general plan, and I am personally persuaded of two things: first, that it is dangerous or even fatal to give saline aperients, especially magnesium sulphate; and second, that expectorants are almost equally undesirable, 
as they promote the flow of mucus and increase the risk of the condition which all must have seen where the patient literally drowns in his own bronchial secretion. .Hence I usually prescribe, in the early stages, quinine and calcium chloride, hoping to keep the air passages dry, with the addition of opium when there is much pleuritic pain. And I expect it is fairly common knowledge that paraldehyde is often most effective with the sleepless pneumonia patient, and especially useful when nearing the crisis.

In the course of time and many epidemics every practitioner's procedure in dealing with influenza tends to stereotype itself. Curiously, I find in conversation with others that we all use different drugs, which would go to show that many are equally useful or useless, but after trying out all sorts of remedies $I$ find that $I$ get earlier relief of symptoms by the administration of quinine and aspirin (and here again neither is as effective by itself) than from any other remedies. The late Sir John Simon taught his students thirty years ago to give quinine and phenacetin, but I now prefer aspirin.

Of the many and varied uses of aspirin in pains and febrile conditions I do not propose to speak-they must be well known; but when thinking of its effects $I$ always recall a case that surprised me. That is the worst of having no scientific explanation of a result. Another doctor once handed orcr to my care a chronic alcoholic of long standing with advanced cirrhosis of the liver and ascites. He was well off, and required to bo tapped at regular intervals. On one occasion this patient complained of rheumatic pain in his shoulder-joint, and I ordered him some aspirin, to find that not only was his shoulder relieved but a diuresis commenced which so completely relieved his ascites that he never required to be tapped again, although his habits had not altered. A few doses of aspirin would always take it down if it showed any sign of return. This case of ascites is again associated in my memory with another of entirely different origin. A girl with advanced pulmonary tuberculosis had been away to a sanatorium at St. Leonards and made a surprisingly good recovery, but some time after her return home began to complain of indigestion and abdominal discomfort. Examination showed considerable free fluid in the abdominal cavity, and a diagnosis of tuberculous peritonitis was made. Treatment by rest and mercurial inunction produced no improvement, but administration of salol acted like a charm; the fluid and symptoms disappeared, and the patient has remained in good health for the last fifteen or mare years. I can only record the observation without explaining the result.

Intestinal Antiscptics: Nerve Sedatives.

We are told that the intestinal antiseptics, so called, do not act as antiseptics to any appreciable extent, and $I$ agree that it does not seem reasonable that they should, but of the uscfulness of many of them in the treatment of intestinal conditions I am perfectly satisfied. Salol in conditions of catarrh or diarrhoea, alike in small children and older people, has come to be one of my sheet-anchors. In cases of gastric catarrh with furred tongue $I$ find that the addition of half a-minim of liquid carbolic acid to the ordinary dose of rhubarb and soda mixture often greatly increases its effectiveness. And again, where this is not effective two or three minims of tineture of iodine will often be helpful. In the treatment: of mucous colitis; besides the use of salol to which I hava referred, many will bo aware of a formula advocated-with great enthusiasm by Dr. Stacey Wilson: liquid perchloride of iron, liquid perchloride of mercury, and tincture of hyoscyamus, of each 15 minims, given half an hour before food. In some cases I have had excellent results with this, but not all patients respond either to this or to salol, and $I$ have then found great benefit in some very severe and prolonged cases from iron and ammonium citrate 5 grains, liquor hamamelidis 15. minims, tincture of opium 2 minims, the opium being omitted where pain and diam hoea are not present. Here again I have taken the formula to pieces and used the bits without getting the results. As a matter of fact I am particularly pleased with the use of this prescription, for it has enabled several chronic and miserable invalids to go to work regularly, and if they occasionally relapse, "the bottle" (as the Scots patient has it) sets them on their feet again.

In these days, when it is so usual, or so fashionable, to suffer from " nerves," it often becomes a problem to know how to help nervy, jumpy, badly sleeping individuals. Bromide is capable of quieting them and helping them to sleep, but is liable to depress them further and may make them dependent on its continued administration. It occurred to me, as it doubtless has to many others, to try adding to the bromide some nux vomica or strychnine. Ircompatible, some will doubtless say; they will cancel one another out; but experience has shown that potassium bromide 10 grains with liquor strychninae 3 minims is most helpful to the type of patient $I$ have in mind. Bromide by itself depresses them; strychnine by itself is deadly for them-they become more jumpy and strung up at once. But the two given together produce calmness without depression, and help them to get back their sleep.

Another use of bromide $I$ have in mind is in the vomiting of pregnancy, which I was taught as a student to treat with stomach sedatives-soda and bismuth-a method I found most disappointing until bromide was added to it. Bromide, perhaps with liquor sedans (P. D. and Co.) I havo always found most effective in the vomiting of pregnancy. Again, all will be familiar with the indigestion of the tired and harassed business man which is immediately relieved by a dose of 10 grains of potassium bromide half an hour before a meal.

To-day the doctor is constantly being offered new remedies that require to be administered hypodermically-a horrible and increasing bugbear to the doctor, though I believe the modern patient expects and likes it. In the treatment of failing heart muscle the administration of adrenaline' is recommended, and we are told that it is only effective when given hypodermically; but I have found that some good result is obtained whon given by the mouth, and I have two cases of mitral disease with failing heart muscle in whom the benefit of digitalis is definitely improved by the addition of adrenaline, so that they, as well as I, can tell at once when it is omitted.

\section{The National Insurance Drug Bill.}

At the beginning of $m y$ address $I$ referred to the great size of the National Health Insurance drug bill, and it would not be inappropriate if I made a reference to cost and economy. It is fortunately a fact that many effective remedies are not expensive, and $I$ find that, by using inexpensive drugs when I can, I am able to order the most costly when I want them without exceeding a reasonable average price. To enumerate a few economies: Tincture of iodine, 5 minims in water, is a cheap and effectivo method of giving iodine in many cases. I so order it in arthritis, adenitis, and thyroid cases, though I do not find it effective as a substitute for potassium iodide in bronehitis or syphilis. Strychnine hydrochloride with chlorofornt or peppermint is an excellent tonic where indicated; as also is Easton's syrup, 30 minims in water. A very useful prescribing discovery was that aspirin is soluble in a solution of potassium citrate; so that it is possible to give these in a mixture and save a separate dispensing fee for tablets or the necessity of suspending the undissolved aspirin.

In concluding what $I$ have described as a dip in a general practitioner's tool-kit $I$ feel that apelogy is needed for presenting. so fragmentary a discourse as a presidential address, but when $\mathbf{I}$ cama to put my experiences together $I$ was not able to find any consecutive schemo or plan on which to hang them. At the same time, I do feel that the publication of their experiences of the effects of the drugs in common use by those who see most of their results, the general practitioners-ought to bo both interesting and useful.

I should like to make one further remark, and that is that in presenting this one aspect of medical treatment I do not wish it to be thought that I am unmindful of the other and frequently more important factors in treatment, but if there are any here who are satisfied that the effects of drugs are mostly psychological, and that a placebof is generally all that is required, then I can only say that $I$ do not agree, and that such is not my experience. 